REVES - Revista Relações Sociais, Vol. 04 N. 01 (2021)

https://periodicos.ufv.br/ojs/reves

doi: 10.18540/revesvl4iss1pp0001-0006ap

OPEN ACCESS - eISSN: 2595-4490

\title{
Ciência e resistência em tempos de pandemia
}

Science and resistance in pandemic times

Roberta Ferreira Coelho de Andrade ${ }^{1}$, Aldair Oliveira de Andrade ${ }^{2}$, Antonio Marcos de Oliveira Siqueira ${ }^{3}$, Wagner dos Reis Marques Araújo ${ }^{4}$

${ }^{1}$ Departamento de Serviço Social, Universidade Federal do Amazonas, Manaus/AM, Brasil, roberta ufam@yahoo.com.br, ORCID: https://orcid.org/0000-0002-6535-0760

2 Programa de Pós-Graduação em Ciências e Humanidades (PPGCH), Universidade Federal do Amazonas, Humaitá/AM, Brasil, aldairandrade@yahoo.com.br, ORCID: https://orcid.org/0000-0001-5205-9766

3 Universidade Federal de Viçosa, Viçosa/MG, Brasil, antonio.siqueira@ufv.br, ORCID: https://orcid.org/0000-0001-9334-0394

4 Universidade do Estado de Minas Gerais, UEMG-Abaeté/MG, Brasil, marquesreis@hotmail.com, ORCID: https://orcid.org/0000-0003-0793-0043

A R T I C L E IN F O

Article history:

Received 2021-01-26

Accepted 2021-01-26

Available online 2021-01-26
Palavras-chave: Conhecimento científico. Covid19. Educação.

Keywords: Scientific knowledge. Covid-19. Education.

Em tempos de pandemia, de genocídio institucionalizado, de espraiamento do conservadorismo e de propagação do discurso anticiência e antivacina, fazer ciência, produzir e socializar conhecimentos se apresentam como atos de rebeldia e resistência, provenientes de uma intelectualidade que não se curvou aos ditames do capital nem à irracionalidade raivosa fascista, por isso, insiste em fazer uso público da razão e não se apequenar ante aos posicionamentos supremacistas, direitistas e fascistas. Se recorrermos a Stanley (2019), entendemos muito bem que o discurso supremacista e anticiência faz parte das estratégias fascistas.

Desde a descoberta do novo coronavírus, no fim de 2019, na China, o vírus SARS-CoV-2, responsável pela pandemia de Covid-19, tem alterado a vida, a saúde física e emocional, a economia, as relações sociais, as dinâmicas de trabalho, as rotinas domésticas, as preocupações com as medidas sanitárias etc. As consequências da pandemia são sentidas nos vários cantos do planeta. Os impactos são sentidos não apenas pelos países pobres, mas também pelas grandes potências capitalistas, que, apesar de disporem de tecnologia de ponta e universidades com 
grandes centros de pesquisa, ainda não têm uma solução definitiva para o enfrentamento definitivo ao vírus. As vacinas produzidas reacendem as esperanças de que o fim da pandemia possa estar no horizonte, por meio da imunização da população, mas não resolvem o problema por completo, visto que ainda não se tem a cura para a Covid-19.

Em alguns países, como Estados Unidos da América e Brasil, o negacionismo e a primazia da economia sobre a preocupação com a vida conduziram a altos índices de infecção, internação e óbitos em decorrência da pandemia (FRESU, 2020). Estados Unidos e Brasil, lamentavelmente, lideram o ranking de mortes por Covid-19, isso porque o nível de testagem da população é extremamente baixo no Brasil. Com isso, as mortes em domicílio e as outras muitas em unidades de saúde, sem que os pacientes tenham feito testagem para o SARS-CoV-2, ficam de fora das estatísticas oficiais.

O negacionismo do governo brasileiro quanto à pandemia ocasionou o distanciamento do Brasil dos processos colaborativos de desenvolvimento de uma vacina contra o vírus que ocasiona a Covid-19. O ano de 2020 foi pautado por aparições públicas, declarações e ações do dirigente máximo do executivo federal que buscaram deslegitimar as orientações científicas, tanto do Organização Mundial de Saúde (OMS), quanto das instituições de pesquisa e organismos no combate à pandemia (RODRIGUES; STAMPA, 2020).

A inexorável evidência de que em maior ou menor tempo a ciência encontraria uma alternativa de combate acirrou o debate, polarizando a discussão entre a negação da doença e sua existência, entre um tratamento "alternativo" sem base científica e o tratamento científico, entre a valorização da vida e a sua banalização.

Anos de pesquisa científica e o compartilhamento de um Banco de Dados produzido por milhares de pesquisadores, liderados por países como Reino Unido, China, Estados Unidos da América e Rússia, aceleraram o processo de criação de algumas vacinas, destacando-se: Oxford/Astrazeneca, Sinovac, Sputinic V.

A criação de vacinas para combate ao SARS-CoV-2 abre patamares de disputa nos campos ideológico, político e econômico. O Brasil, por sua atitude negacionista e reativa, ficou alijado do processo de disputa no mercado mundial por vacinas para sua população, o que vai atrasar consideravelmente as etapas de imunização de sua população, tendo como consequências trágicas: aumento significativo da mortalidade, 
da contaminação, de doenças decorrentes, o desenvolvimento de novas cepas devido ao alto índice de transmissão comunitária e o aparecimento cíclico de ondas de contaminação e mortes.

Na perspectiva interna, o Brasil é palco de narrativas político-ideológicas sobre o desenvolvimento e o investimento em produção de vacinas. O Governo Federal aposta no fracasso político e científico do investimento feito pelo Estado de São Paulo na produção de vacina em parceria do Instituto de Pesquisa Butantan com a Chinesa Sinovac; por seu turno, não fez nenhuma parceria interna ou externa para o desenvolvimento de uma vacina. Não seria demais afirmar que o Governo Brasileiro assumiu deliberadamente a naturalidade da pandemia e suas consequências, mantendo uma atitude de negação e disseminação do discurso de retorno à "normalidade" econômica e social.

Alguns fatos políticos e econômicos são característicos da disputa de narrativas sobre a pandemia no Brasil. Destes merecem destaque: a) a "improvisada" medida do Congresso Nacional em aprovar o "Auxílio Emergencial" a todos os brasileiros em condições de vulnerabilidade social à revelia e contragosto do Palácio do Planalto; b) o boicote sistemático das orientações da OMS e do Ministério da Saúde pelo Palácio do Planalto, seja por manifestações públicas dissonantes, seja pela interferência administrativa e substituição do staff e do corpo técnico por militares de carreira, sem quaisquer formação nas áreas da saúde; c) a defesa intransigente e inconsequente de tratamentos com substâncias sem nenhuma comprovação científica de eficácia (como cloroquina e ivermectina); d) disputa entre o Palácio do Planalto e os Governadores sobre o combate à pandemia, sendo necessário o Supremo Tribunal Federal (STF) dirimir a questão deixando claras as atribuições de cada ente da federação. Diga-se, de passagem, que a manifestação do STF sobre a matéria é usada de forma enviesada pelo Planalto para se eximir da responsabilidade e da coordenação nacional do combate à pandemia.

Entre os diversos capítulos trágicos da pandemia no Brasil, destaca-se o vivido pelo Estado do Amazonas/Brasil, com maior incidência na capital Manaus. Após os duros meses de abril e maio de 2020, o Amazonas entrou numa onda ufanista de que o "pior já tinha passado", como declararam autoridades públicas, levando a população a crer que tínhamos chegado ao "fim da pandemia no Amazonas". Esse sentimento assessorado pela pressão da economia pelo retorno à "normalidade", das escolas privadas e públicas pela retomada das aulas, pelo comportamento vacilante das 
entidades de controle, pelo Governo do Estado - ensejou uma espécie de pouco caso com os cuidados sanitários da população de modo geral.

As campanhas eleitorais, a realização das eleições municipais, as festividades de natal e ano novo, além da abertura de espaços de festas, balneários, casas noturnas, feiras, igrejas e templos, entre outros, produziram intensas aglomerações da população por todo o país. Em Manaus, os reflexos desse conjunto de elementos foram duramente sentidos a partir de janeiro de 2021.

$O$ ano de 2021 começou com Manaus sendo novamente o centro da manchete nacional e internacional. Uma nova variante do SARS-CoV-2 (com acelerado processo de manifestações de sintomas e maior transmissibilidade) estava em plena contaminação (NAVECA et. al., 2021), saturando o sistema público e privado de saúde (CNN BRASIL, 2021), como também aumentando significativamente o número de óbitos, que havia decrescido no segundo semestre de 2020. As medidas tardias do governo estadual foram incapazes de frear a nova onda. O sistema de saúde colapsou e Manaus se tornou uma sepultura a céu aberto.

O risco iminente de uma segunda onda foi bradado por pesquisadores da Fundação Oswaldo Cruz (FIOCRUZ) - Centro de Pesquisa Leônidas e Maria Deane, bem como pelo doutorando do Instituto Nacional de Pesquisas da Amazônia (INPA), Lucas Ferrante, mas houve descaso ante as denúncias sobre a possiblidade de uma segunda onda e o desmonte dos hospitais de campanha construídos na primeira onda etc. Evidenciou-se, assim, em janeiro de 2021, que a segunda onda não era uma possibilidade remota e sim uma realidade trágica e dramática. O referido doutorando alertou, já no mês de fevereiro de 2021, que sem a adoção do lockdown extensivo e sem vacinação de, pelo menos, $70 \%$ da população, há um risco de uma terceira onda (A CRÍTICA, 2021).

Se verificarmos os casos confirmados de Covid a partir do segundo semestre de 2020 até o dia 01 de fevereiro de 2021 na capital amazonense, identificaremos um crescimento significativo, tanto no nível de casos confirmados, talvez por conta da retomada das testagens, como dos casos de internações e mortalidade.

Em junho de 2020, a Fundação de Vigilância em Saúde (FVS) do Amazonas informava que havia 41.774 casos de SARS-CoV-2 confirmados; no mês seguinte houve um salto para 72.284 , o que representava um crescimento de $73 \%$ em relação ao mês anterior. Os dados apresentam uma queda nos meses seguintes, com 
ascendência a partir de janeiro de 2021. Essa mesma tendência é observada nos casos de óbitos, com 2.071 casos confirmados em junho de 2021 e 2843 em julho, registrando-se um crescimento de 37\% em relação ao mês anterior. Identifica-se uma queda da mortalidade nos meses seguintes, com um crescimento exponencial no início do mês de fevereiro de 2021.

Entre todas as variáveis que irão contribuir para o colapso e o aumento significativo do número de mortes na capital e interior do Estado, identifica-se a falta de um componente básico e vital para o atendimento da rede hospitalar: o oxigênio $\left(\mathrm{O}_{2}\right)$ (BRASIL 247, 2021). Sobre seu fornecimento, a empresa responsável por seu suprimento às unidades de saúde do Estado, White Martins, informou que o consumo médio - que esteve durante o pico da primeira onda (abril e maio de 2020) na casa dos $30.000 \mathrm{~m}^{3}$ - saltou muito rapidamente para $73.000 \mathrm{~m}^{3}$ diários no início de janeiro de 2021. Tal consumo excede em quase três vezes a capacidade de produção instalada, segundo a fornecedora, que é de $23.000 \mathrm{~m}^{3}$ diários.

Os fatos têm demonstrado que o Estado do Amazonas é a prova concreta da falta de uma política séria de combate à pandemia, seja pelos governos locais, seja por parte do Governo Federal. Não é exagero ressaltar a grande probabilidade de que o que hoje se torna uma experiência nefasta no Estado de Amazonas venha a se repetir em outros Estados da federação, com maior ou menor grau de fatalidades, pois, de modo geral, o mesmo modus operandi de combate à pandemia foi executado no território nacional, pelo Ministério da Saúde, pelas Secretarias Estaduais e Municipais de Saúde e pelas agências de vigilância sanitária. De fato, não levaram a sério a possibilidade de uma segunda onde de contaminação e não se prepararam para essa eventualidade que se tornou concreta e tem Manaus como seu epicentro.

Julgamos essa contextualização importante e necessária porque a Revista Relações Sociais - REVES não está de costas para a realidade mundial e brasileira. Mais do que nunca e, sobretudo num cenário de ataque ferrenho e sistemático à ciência e aos pesquisadores, este periódico reafirma sua fidelidade aos princípios científicos e sua confiança na ciência.

Em seus 4 anos de existência, a REVES nunca se furtou à reflexão, de modo crítico, interdisciplinar e plural, abrindo suas várias edições ao debate da educação, da política, da diversidade cultural e sexual, da filosofia, da sociologia, das humanidades, das engenharias etc., por entender que os diferentes saberes são 
fundamentais ao desvelamento e à transformação da realidade social, política e econômica do país.

$\mathrm{Na}$ edição $\mathrm{n}^{\mathrm{0}}$ 1, do volume 4, traz um conjunto de 16 artigos com discussões sobre pandemia, educação, estratégias pedagógicas, controle social, democracia, filosofia e engenharia ambiental. Nesse sentido, convidamos os leitores a fazerem um passeio epistemológico nesta edição. Boa leitura!

\section{REFERÊNCIAS}

A CRÍTICA. Em Manaus, cientista pede 'lockdown e parlamentares querem flexibilização. A Crítica. Disponível em: Em Manaus, cientista pede 'lockdown' e parlamentares querem flexibilização | Coronavírus | A Crítica| Amazônia - Amazonas - Manaus (acritica.com). Acesso em 10 fev. 2021.

BRASIL 247. Famílias realizam filas para comprar oxigênio em empresas privadas em Manaus. Brasil 247. 16 jan. 2021. Disponível em: Famílias realizam filas para comprar oxigênio em empresas privadas em Manaus - Brasil 247. Acesso em: 26 jan. 2021.

CNN BRASIL. Situação do Amazonas sobre Covid-19. Disponível em: https://www.cnnbrasil.com.br/nacional/2021/01/08/entenda-por-que-a-situacao-de-manaus-e mais-grave-do-que-a-de-outras-capitais. Acesso em: 09 jan. 2021.

FRESU, Gianni. Entre pandemia e crise orgânica: contradições e narrações hegemônicas do capitalismo em colapso. In: LOLE, Ana; STAMPA, Inez; GOMES, Rodrigo Lima R. (Orgs.). Para além da quarentena: reflexões sobre crise e pandemia. Rio de Janeiro: Mórula, 2020, p. $42-53$

MBEMBE, A. Necropolítica. Arte \& Ensaios. n. 32, dez. 2016, p. 122-151. Disponível em: https://revistas.ufrj.br/index.php/ae/article/view/8993. Acesso em: 05 jan. 2021.

NAVECA, F. et al. Reinfecção do SARS-CoV-2 pelo novo Variant onf Concern (VOC) P.1 no Amazonas, Brasil. 17 jan. 2021. Disponível em: https://virological.org/t/sars-cov-2reinfection-by-the-new-variant-of-concern-voc-p-1-in-amazonas-brazil/596. Acesso em: 30 jan. 2021.

RODRIGUES, Vicente A. C.; STAMPA, Inez. A pandemia e a 'inteligência' do presidente. In: LOLE, Ana; STAMPA, Inez; GOMES, Rodrigo Lima R. (Orgs.). Para além da quarentena: reflexões sobre crise e pandemia. Rio de Janeiro: Mórula, 2020, p. 82-92.

STANLEY, Jason. Como funciona o fascismo: a política do "nós" e "eles". Porto Alegre: LP\&M, 2019. 